\title{
Barium sulfate precipitation as model reaction for segregation studies at pilot scale
}

\author{
T. Meyer*, P.-A. Fleury, A. Renken \\ Institut de Génie Chimique, Ecole Polytechnique Fédérale de Lausanne, Lausanne (Switzerland)
}

J. Darbellay and P. Larpin

Ciba-Geigy, Dép. Matières Plastiques, Usine de Monthey, Monthey (Switzerland)

(Received January 3, 1992; in final form May 27, 1992)

\begin{abstract}
The precipitation of barium sulfate from a basic EDT $\Lambda$-complex upon addition of a small volume of acid in a stirred tank reactor has been used as a model reaction to study the local state of micromixing. Limitations and modifications of this reaction are presented here and its application on an industrial pilot scale is realized. A higher reaction rate is used in order to decrease the reaction time using different concentrations of reactants which modify the stability of the precipitate. A study of this stability is presented here.
\end{abstract}

\section{Introduction}

Micromixing can be defined as the contact and mixing of fluids at the molecular scale. The characterization and understanding of these phenomena are of special importance for industrial processes: micromixing may control the yield and selectivity of chemical reactors in which mixing and reactions occur simultaneously with comparable rates. Examples are polymerisation in high viscous medium, precipitation or fast combustions.

To characterize segregation in homogeneous systems several authors [1-3] propose consecutive competing reactions. The reactants are fed separately into the reactor in order to create initially high concentration gradients. The first reaction forming the intermediate product should be fast compared to the second one, which has a rate comparable to the micromixing process.

$\mathrm{A}+\mathrm{B} \stackrel{k_{1}}{\rightarrow} \mathrm{R}$

$\mathrm{R}+\mathrm{B} \stackrel{k_{2}}{\longrightarrow} \mathrm{S}$

$k_{1} \gg k_{2}, \quad\left(n_{\mathrm{A} 0}>n_{\mathrm{B} 0}\right)$

If a limited amount of $\mathrm{B}\left(n_{\mathrm{B} 0}\right)$ is added to an excess of $\mathrm{A}\left(n_{\mathrm{A} 0}\right)$, the intermediate $\mathrm{R}$ is immediately formed and $B$ is totally consumed at the end of the reaction. Under ideal micromixing conditions, the formation of $S$ is

*Author to whom correspondence should be addressed. quite insignificant owing to the instantaneous dispersion of $B$ and its stoichiometric deficit. On the contrary, if the fluid is partially segregated, B is locally in stoichiometric excess in contact with $\mathrm{R}$ which is thus converted to the final product $S$. Therefore, the amount of $\mathrm{S}$ formed is a measure of the degree of segregation. For the practical use of a model reaction, a trace of the history of mixing must be kept in the system in form of the stable end product. In this way the system retains a memory of the micromixing process which takes place during the lifetime of segregated eddies. As proposed by Bourne et al. $[4,5]$, the yield of $\mathbf{S}$ may be considered as a segregation index for the system:

$X_{\mathrm{s}}=\frac{2 C_{\mathrm{s}}}{\left(2 C_{\mathrm{s}}+C_{\mathrm{R}}\right)}$

Besides the well studied azo-coupling of 1-naphthol with diazotised sulfanilic acid $[1,6]$, the precipitation of barium sulfate (S) from a basic EDTA-complex (A) under the influence of acid (B) has been proposed by Barthole et al. [2] and Villermaux [7]. The reaction scheme can be summarized as follows $[3,8]$

$\mathrm{A}+\mathrm{B} \stackrel{{ }^{1}}{\longrightarrow} \mathrm{R}+\mathrm{W}$

$n \mathrm{U}+\mathbf{R}+2 \mathbf{B} \stackrel{k_{2}}{\longrightarrow} n \mathrm{~S}+n \mathrm{~T}$

with

$\mathrm{A}=\left(\mathrm{Ba}^{2+}, \mathrm{Y}^{4-}\right)_{n} \mathrm{OH} ; \quad \mathrm{B}=\mathrm{H}^{+}$;

$\mathrm{R}=\left(\mathrm{Ba}^{2+}, \mathrm{Y}^{4-}\right)_{n} ; \mathrm{W}=\mathrm{H}_{2} \mathrm{O} ; \mathrm{U}=\mathrm{SO}_{4}^{2-}$ 
$\mathrm{S}=\mathrm{BaSO}_{4} ; \quad \mathrm{T}=\mathrm{Y}^{4-}, 2 \mathrm{H}^{+}$<smiles>[Y]OC(=O)CN(CCN(CC(=O)[O-])CC(=O)O[Na])CCN(CC(=O)[O-])CC(=O)O[Na]</smiles>

The alkaline solution is prepared using $\mathrm{BaCl}_{2}, \mathrm{NaOH}$, $\mathrm{Na}_{2} \mathrm{SO}_{4}$, and the sodium salt of EDTA. Protons are added in the form of a dilute $(0.1 \mathrm{~N}) \mathrm{HCl}$ solution.

To use the proposed model reaction for different mixing devices and varying micromixing time $\left(t_{\mathrm{m}}\right)$, the characteristic reaction time $\left(t_{\mathrm{r}}\right)$ has to be modified to get $t_{\mathrm{r}} \approx t_{\mathrm{m}}$. Barthole et al. $[2,10]$ studied the reaction under defined experimental conditions, giving a characteristic reaction time of approximately $t_{\mathrm{r}}=3 \mathrm{~s}$ [9], thus limiting the use of the test reaction to mixers with mixing times in the same order of magnitude. The present study will focus on changing reactant concentrations in order to decrease $t_{r}$. The upper limit, due to instabilities of the reactant solutions will be shown. Finally local micromixing intensities were measured in an industrial pilot reactor of $0.160 \mathrm{~m}^{3}$ volume for various mixer types.

\section{Kinetics of the model reaction}

The first step of reaction 3 is a neutralization reaction and can be considered as instantaneous $\left(k_{1}=1.8 \times\right.$ $10^{8} \mathrm{~m}^{3} \mathrm{~mol}^{-1} \mathrm{~s}^{-1}$, [3]) compared to the second one [3].

$r_{2}=k_{2} C_{\mathrm{R}} C_{\mathrm{U}} \quad$ with $k_{2}=k_{0} C_{0}^{2 / 3}$

$k_{0}=1.9 \times 10^{-2} \mathrm{~m}^{5} \mathrm{~mol}^{-5 / 3} \mathrm{~s}^{-1}$

$C_{0}$ is the concentration of available sites for the crystallization of $\mathrm{BaSO}_{4}$ :

$C_{0}=C_{\mathrm{S} 0}+\frac{1}{2}\left(n C_{\mathrm{A} 0}+n C_{\mathrm{U} 0}-\left|n C_{\mathrm{A} 0}-n C_{\mathrm{U} 0}\right|\right)$

The characteristic reaction time is defined as

$t_{\mathrm{r}}=\left(k_{0} C_{\mathrm{U} 0} C_{0}^{2 / 3}\right)^{-1}$

Thus the reaction time $t_{\mathrm{r}}$ can be adjusted to the actual mixing system by changing the concentration of Barium- and/or Sulfate-ions as shown in Fig. 1.

Unfortunately, a stoichiometric amount of EDTA is not sufficient to prevent $\mathrm{BaSO}_{4}$ precipitation in the complex mixture even before adding protons. The prepared solutions become turbid and are no longer suitable for the segregation measurements.

On the contrary, if the chosen EDTA concentration is too high, the once precipitated $\mathrm{BaSO}_{4}$ after injection of the acid is redissolved and the reaction system loses its memory.

Therefore a compromise has to be found in order to prevent precipitation and redissolution in a reasonable time interval needed for the experimental studies. This time interval was fixed to about one hour.

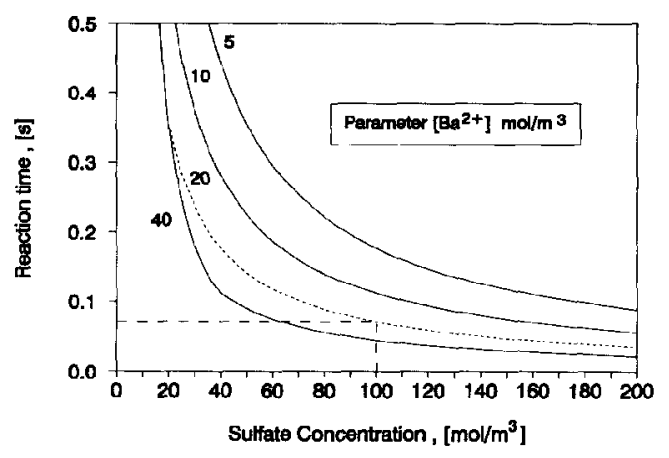

Fig. 1. Reaction time of the test reaction.

For the planned experiments a characteristic reaction time of $t_{\mathrm{r}} \leqslant 0.1 \mathrm{~s}$ was necessary. According to Fig. 1 the following concentrations were used:

$\left[\mathrm{Ba}^{2+}\right]=20 \mathrm{~mol} \mathrm{~m}^{-3}, \quad\left[\mathrm{SO}_{4}^{2-}\right]=100 \mathrm{~mol} \mathrm{~m}^{-3}$

Adding a small amount of $\mathrm{HCl}$-solution induced $\mathrm{BaSO}_{4}$ precipitation. The concentration of the precipitate was determined by light absorption in a spectrophotometer. In Fig. 2 the absorbance is shown as function of time for different concentrations of EDTA.

Threc fields can be distinguished:

[EDTA] $<38 \mathrm{~mol} \mathrm{~m}^{-3}$ The absorbance is growing with the time, the precipitation is going on without any additional acid.

$38<$ [EDTA] $<42 \mathrm{~mol} \mathrm{~m}^{-3}$ The absorbance is quite constant, the maximal variation in one hour is $5 \%$.

[EDTA] $>42 \mathrm{~mol} \mathrm{~m}^{-3}$ A large decrease in absorbance is measured signifying a redissolution of the precipitate.

As a consequence, the EDTA-concentration was fixed to $40 \mathrm{~mol} \mathrm{~m}^{-3}$. This condition allows a sufficient stability of the suspensions formed and reproducible results for the segregation index $\left(X_{s}\right)$.

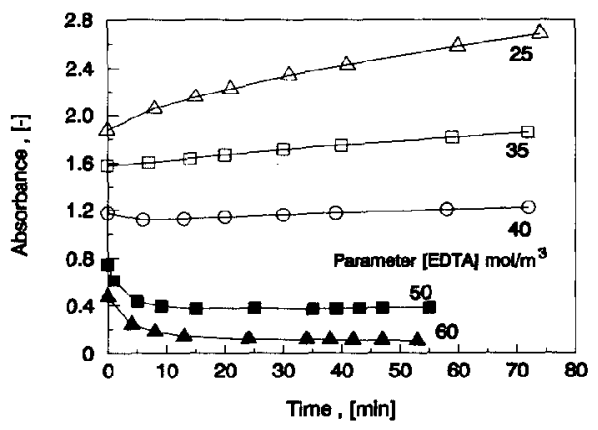

Fig. 2. Stability of the formed precipitate as a function of time. 
For solutions with higher concentrations of $\mathrm{Ba}^{2+}$ and $\mathrm{SO}_{4}^{2-}$ satisfactory conditions for the test reaction could not be found. The minimal characteristic reaction time obtained for segregation measurement is therefore in the order of $t_{\mathrm{r}}=0.1 \mathrm{~s}$.

\section{Experimental determination of segregation}

The test reaction is used to study the segregation characteristic of a pilot plant stirred tank with a volume of $V_{\mathrm{r}}=0.160 \mathrm{~m}^{3}$ equipped with two types of stirrer, an anchor and a three stages Intermig. The rotation speed can be varied between $N=45-115$ and $N=100-$ 290 RPM respectively.

The tank initially contains an aqueous BariumEDTA solution under basic conditions and a small amount of barium sulfate crystals. This solution is prepared in a $2 \mathrm{~m}^{3}$ tank (see Fig. 3, zone $\mathrm{A}$ ). The experimental conditions are summarized in Table 1.

At a specified point in the tank a solution of $2 \mathrm{~N}$ hydrochloric acid is pumped for a limited time. The injection tube has an inner diameter of $2.5 \mathrm{~mm}$. To be sure that the measured phenomena is due to micromixing, the injection time for the acid is varied in a broad range from 3-15 minutes. The flow rate is adapted to maintain the total amount of acid injected to $600 \mathrm{~g}$. Atter the injection a sample of $250 \mathrm{ml}$ is taken to determine the precipitated $\mathrm{BaSO}_{4}$ by light absorption at a wave length of $650 \mathrm{~mm}$. The absorbance measurement of the same sample is repeated about six times over a

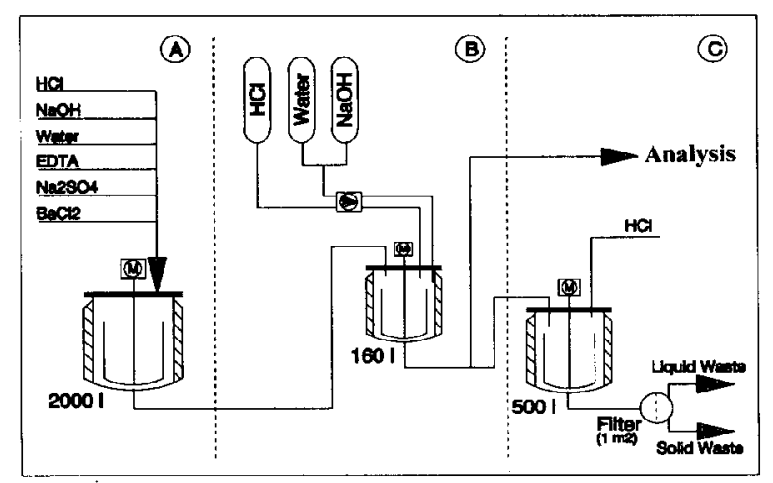

Fig. 3. Experimental set-up.

TABLE 1. Experimental conditions.

$\begin{array}{ll}{\left[\mathrm{Ba}^{2}\right]_{0}=20 \mathrm{~mol} \mathrm{~m}^{-3}} & {\left[\mathrm{BaSO}_{4}\right]_{0}=10^{-4} \mathrm{~mol} \mathrm{~m}^{-3}} \\ {\left[\mathrm{EDTA}_{0}=40 \mathrm{~mol} \mathrm{~m}^{-3}\right.} & {\left[\mathrm{HI}^{+}\right]_{0}=2 \mathrm{~N}} \\ {\left[\mathrm{SO}_{4}{ }^{2-}\right]_{0}=100 \mathrm{~mol} \mathrm{~m}^{-3}} & \mathrm{pII}=12\end{array}$
$\mathrm{t}_{\mathrm{r}}=0.07 \mathrm{~s}$ time interval of $20 \mathrm{~min}$ to check the stability of the solution.

After an experiment the used solution is pumped to a precipitation tank to eliminate the barium sulfate as a solid waste. The EDTA containing solution is sent to the biological waste water treatment (Fig. 3, zone C).

\section{Results and discussion}

Typical segregation data are shown in Figs. 4 and 5 for the anchor stirrer at a stirrer speed of $45 \mathrm{rpm}$. The segregation index depends on the location of the injection point and varies from $1.9 \%-6.1 \%$. The highest mixing intensity is on the upper point of the anchor. Injection of the reactant on the surface or in the lower parts of the reactor is less favourable.

As expected, the segregation depends strongly on the stirrer speed as shown in Fig. 6. For three different angles of $\beta=123,135$ and 180 the dependence of $X_{\mathrm{s}}$ as a function of the stirrer speed is represented. Similar results are obtained for the Intermig which can not be published. High mixing intensities are observed near the edge of the blade of the stirrer and just behind or before the baffles.

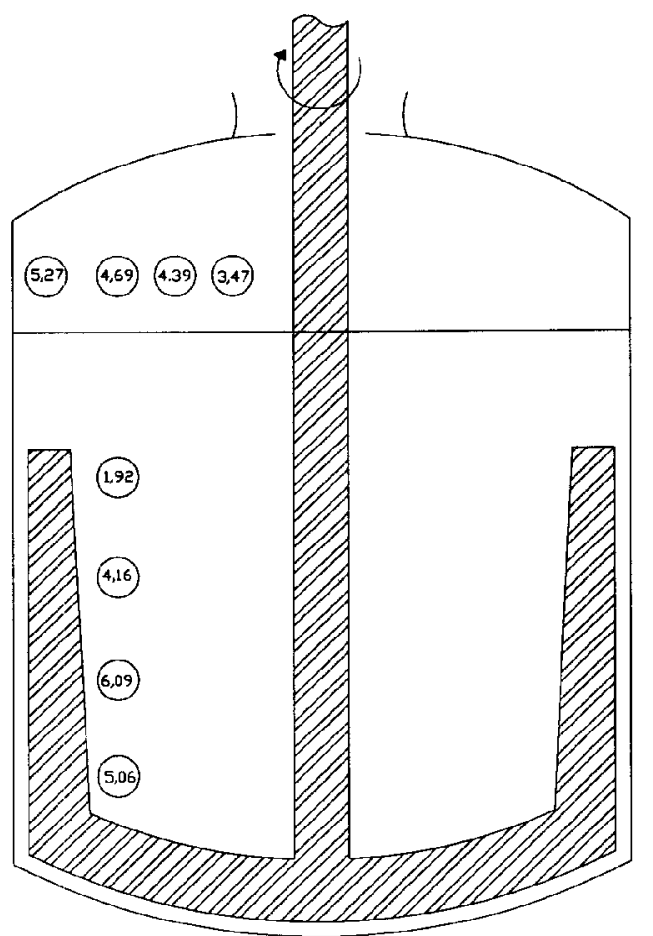

Fig. 4. Segregation index in $\%$ for the anchor stirrer at $N=45 \mathrm{rpm}$. 


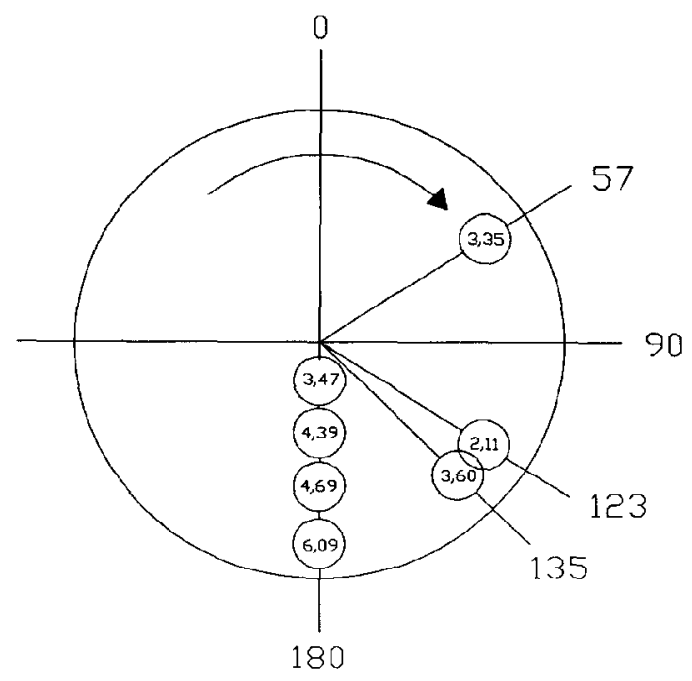

Fig. 5. Segregation index in $\%$ for the anchor stirrer at $N=45 \mathrm{rpm}$, horizontal plane. $\beta=90$ corresponds to the position of the inner baffle.

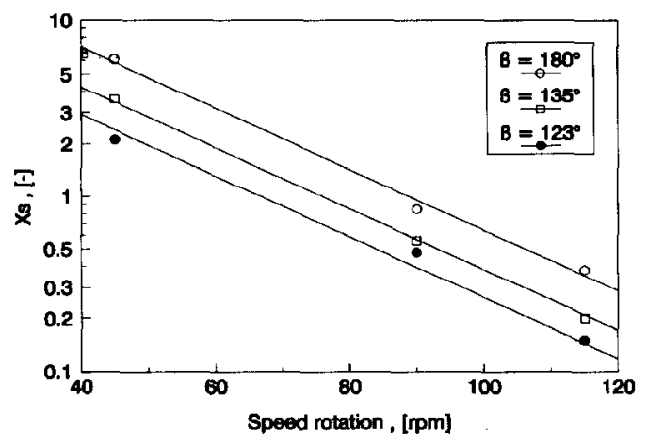

Fig. 6. Effect of the stirrer speed on the segregation index.

\section{Conclusion}

The precipitation of $\mathrm{BaSO}_{4}$ in the presence of EDTA by adding an acid is a simple method for measuring local states of micromixing in a stirred tank. The great advantage of this method is the potential low cost of the products and the ease to measure the segregation index. Nevertheless, the limit of the test reactions is due to the stability of the basic sulfate solution at high concentration and to the redissolution of the crystals after precipitation. The goal of the present communica- tion is therefore to show the extreme conditions and the shortest characteristic reaction time $(0.07 \mathrm{~s})$ obtained without experimental difficulties.

\section{Nomenclature}

$\begin{array}{ll}\text { ABS } & \text { absorbance } \\ C & \text { concentration, mol } \mathrm{m}^{-3} \\ k & \text { reaction rate constant, variable dimension } \\ l & \text { length, m } \\ n & \text { stoichiometric coefficient } \\ N & \text { rotation speed, rpm } \\ t_{\mathrm{m}} & \text { mixing time } \\ t_{\mathrm{r}} & \text { reaction time } \\ V & \text { volume, } \mathrm{m}^{3} \\ X_{\mathrm{s}} & \text { segregation index } \\ \varepsilon & \text { extinction coefficient }\end{array}$

\section{References}

I J. R. Bourne, F. Kozicki and P. Rys, Mixing and fast chemical reaction I: Test reactions to determine segregation, Chem. Eng. Sci., 36 (1981) 1643-1648.

2 J. P. Barthole, R. David and J. Villermaux, A new chemical method for the study of local micromixing conditions in industrial stirred tanks, ACS Symp. Ser., 196 (1982) 545-553.

3 J. P. Barthole, R. David, J. F. Molleyre, P. Bourret and J. Villermaux, Cinétique macroscopique de la précipitation du $\mathrm{BaSO}_{4}$ en présence d'EDTA: Une réaction chimique-test pour la caractérisation de la qualité du mélange dans les réacteurs industriels, J. Chimie Physique, 79 (1982) 719-724.

4 J. R. Bourne and S. Rohani, Micro-mixing and the selective iodination of 1-Tyrosine, Chem. Eng. Res. Des., 61 (1983) 297-302.

5 J. Baldyga and J. R. Bourne, A fluid mechanical approach to turbulent mixing, Chem. Eng. Commun., 28 (1984) 231-241.

6 J. R. Bourne, Micromixing revisited, I. Chem. E. Symp. Ser., 87 (1984) $797-814$.

$7 \mathrm{~J}$. Villermaux, Micromixing phenomena in stirred reactors, Encycl. of Fluid Mechanics, Chap. 27, Gulf Publishing, Houston, TX, 1986, 707-771.

8 R. David, H. G. Lintz and J. Villermaux, Untersuchung der Durchmischung in kontinuierlich betriebenen Reaktoren mit Hilfe von chemischen Reaktionen, Chem. Ing. Techn., 56 (1984) $104 \quad 110$

9 T. Meyer, R. David, J. Villermaux and A. Renken, Micromixing in a static mixer and an empty tube by a chemical method, Chem. Eng. Sci., 43 (1988) 19551960.

$10 \mathrm{R}$. David and $\mathbf{J}$. Villermaux, Interpretation of micromixing effects on fast consecutive-competing reactions in semi-batch stirred tanks by a simple interaction model, Chem. Eng. Comm., 54 (1987) 333-352. 